\title{
Sustentabilidade em Prédios e 0bras Públicas: Análise em uma Instituição de Ensino Superior
}

\author{
Dailleny Chagas de Oliveira Marianol; Aline Guimarães Monteiro Trigol; Úrsula Gomes Rosa \\ Maruyamal
}

凹daillenymariano@gmail.com

1. Centro Federal de Educação Tecnológica Celso Suckow da Fonseca - CEFET/RJ.

\author{
Histórico do Artigo: \\ Recebido em: 13 de maio de $2020 \quad$ Aceito em: 16 de setembro de $2020 \quad$ Publicado em: 30 de abril de 2021
}

\begin{abstract}
Resumo: 0 crescimento econômico no mundo atraiu as grandes indústrias e induziu a população a um consumo acelerado. Com isso, houve um desequilíbrio no qual a sociedade passou a conviver com a desigualdade, gerando uma preocupação com a qualidade de vida humana associada à escassez de recursos naturais. Da mesma maneira, as construções começaram a acelerar, sem planejamento e acarretaram diversos tipos de impactos ambientais. 0s governos optaram por incentivar práticas sustentáveis e buscaram adequar-se a uma relação de melhor custobenefício. Neste contexto, leis são elaboradas e impõem a utilização de recursos renováveis e a redução de materiais, além do incentivo à economia do reaproveitamento. Por isso, este artigo tem como objetivo criar uma agenda de critérios de sustentabilidade para projetos de obras em uma instituição de ensino superior, como 0 Centro Federal de Educacão Tecnológica Celso Suckow da Fonseca (CEFET/RJ), tendo como referência os documentos exigidos pela Administração Pública Federal (IN n ${ }^{0}$ 01/2010 e a Lei nº 111/2011), a partir de uma pesquisa qualitativa e exploratória. 0s primeiros resultados, a partir das análises observadas, demonstram que três quartos dos critérios são atendidos. Contudo, torna-se necessário um estudo aprofundado para que todos os critérios, colocados em lei, sejam atendidos e viabilizados durante a concepção do projeto de arquitetura com a participação, em conjunto, das equipes de licitação, de orçamento e dos projetos complementares.
\end{abstract}

Palavras-chave: Critérios sustentáveis, Construção civil, Administração pública, Responsabilidade.

\section{Sustainability In Buildings And Public Works: Analysis In An Higher Educational Institution}

Abstract: Economic growth in the world has attracted large industries and induced the population to accelerate consumption. Thus, there was an imbalance in which society started to live with inequality, generating a concern with the quality of human life associated with the scarcity of natural resources. In the same way, constructions began to accelerate, unplanned, causing various types of environmental impacts. Governments have chosen to encourage sustainable practices and sought to adapt to a better cost-benefit ratio. In this context, laws are drafted and require the use of renewable resources and the reduction of materials, in addition to encouraging reuse savings. Therefore, this article aims to create an agenda of sustainability criteria for construction projects in a higher education institution, such as Celso Suckow da Fonseca Federal Center for Technological Education (CEFET/RJ), having as reference the documents required by Federal Public Administration (IN n ${ }^{0} 01 / 2010$ and Law $\left.\mathrm{n}^{0} 111 / 2011\right)$, based on a qualitative and exploratory research. The first results, from the observed analyzes, show that three quarters of the criteria are met. However, an in-depth study is necessary to ensure that all the criteria, laid down by law, are met and made feasible during the design of the architectural project with the participation, jointly, of the bidding, budget and complementary projects teams.

Keywords: Sustainable criteria, Civil construction, Public administration, Responsibility. 


\section{Sostenibilidad En Edificios Y Obras Públicas: Análisis En Una Institución De Educación Superior}

Resumen: El crecimiento económico en el mundo ha atraído a grandes industrias e inducido a la población a acelerar el consumo. Como resultado, hubo un desequilibrio en el cual la sociedad comenzó a vivir con desigualdad, generando una preocupación por la calidad de vida humana asociada con la escasez de recursos naturales. Del mismo modo, las construcciones comenzaron a acelerarse, sin planificación y tuvieron varios tipos de impactos ambientales. Los gobiernos decidieron fomentar prácticas sostenibles y buscaron adaptarse a una mejor relación costo-beneficio. En este contexto, las leyes se redactan e imponen el uso de recursos renovables y la reducción de materiales, además de fomentar la economía de la reutilización. Por lo tanto, este artículo tiene como objetivo crear una agenda de criterios de sostenibilidad para proyectos de construcción en una institución de educación superior, como el Centro Federal de Educación Tecnológica Celso Suckow da Fonseca (CEFET / RJ), teniendo como referencia los documentos requeridos por Administración Pública Federal (IN nº 01/2010 y Ley n 11l/2011), basada en una investigación cualitativa y exploratoria. Los primeros resultados, de los análisis observados, demuestran que se cumplen las tres cuartas partes de los criterios. Sin embargo, es necesario un estudio en profundidad para que todos los criterios, establecidos por ley, se cumplan y sean factibles durante el diseño del proyecto arquitectónico con la participación, conjuntamente, de los equipos de licitación, presupuesto y proyectos complementarios.

Palabras clave: Criterios sostenibles, Construcción civil, Administración pública, Responsabilidad.

\section{INTRODUÇ̃̃o}

A preocupação com o meio ambiente e o reconhecimento da existência de impactos ambientais negativos gerados em todas as fases do ciclo de vida de uma obra refletem-se nos objetivos e princípios das políticas e normas ambientais brasileiras.

Sabe-se que a gestão ineficiente de cada uma das etapas (planejamento, implantação, uso, manutenção e demolição) da edificação agrava os impactos ambientais, assim como os custos e o volume de resíduos sólidos, causando prejuízos à sociedade. Contudo, a escolha neste artigo pela etapa de planejamento da obra se verifica, pois é a etapa na qual serão decididas todas as intervenções que poderão integrar a obra ao meio ambiente ou resultar em danos em curto, médio e longo prazo. Algumas intervenções estão relacionadas aos estudos de viabilidade financeira, física e econômica, elaboração de projetos e suas especificações e 0 desenvolvimento das atividades construtivas com seus cronogramas (COSTA; MORAES, 2013). A partir destes estudos, são delineadas estratégias que levem em conta a efetividade energética, o baixo impacto ambiental pela seleção dos materiais, a conservação da água, saúde e bemestar do cliente e o conforto ambiental interno; de maneira que seja atestada a qualidade do empreendimento.

A elaboração dos projetos básico e executivo deve ser vista como uma grande oportunidade de atuação preventiva, uma vez que há possibilidades de serem feitos ajustes 
visando à melhoria e a ecoeficiência do empreendimento, por meio da incorporação de critérios sustentáveis, especialmente em seu planejamento, o que colabora no desenvolvimento de uma construção civil sustentável.

0 conceito da sustentabilidade na construção civil vem ganhando força, pois cresce a preocupação com o ecologicamente correto, com a longevidade e harmonia de interação entre o "edificar" e a natureza. A publicação do Conselho Brasileiro de Construção Sustentável (2014, p.73) afirma que este setor é responsável por consumir "mais da metade dos recursos naturais extraídos do planeta na produção e manutenção do ambiente construído" e neste quesito surge a preocupação em procurar alternativas sustentáveis para se construir. Sintetizando, buscase agregar mais valor ao empreendimento, quando atende às demandas, de forma mais efetiva, das partes interessadas e alcança uma melhor qualidade de vida para a sociedade hoje, sem comprometer as gerações futuras.

Por isso, o estudo percebe a necessidade de conhecer uma agenda de critérios sustentáveis para auxiliar na construção e reforma de futuros prédios públicos no Centro Federal de Educação Tecnológica Celso Suckow da Fonseca (CEFET/RJ), modificando e incentivando a utilização de recursos ecoeficientes, transformando a percepção daqueles que fazem uso da edificação e enfatizando a importância de estimular as mudanças na região.

Nos próximos tópicos do artigo, destaca-se a importância de entender os conceitos de sustentabilidade voltados para a construção civil para que dessa forma seja possível alcançar maior eficiência quanto às características dos produtos utilizados e eficácia quanto ao planejamento elaborado para a construção por meio dos projetos. Mais adiante, ressalta-se a inserção da sustentabilidade na Administração Pública, por meio do programa voluntário do MMA, conhecido por Agenda Ambiental na Administração Pública (A3P), que se aplica aos órgãos públicos e atua nas três esferas federal, estadual e municipal, e nos poderes executivo, legislativo e judiciário. Estrutura-se em seis eixos temáticos fundamentados pela política dos 5 R's (Repensar, Reduzir, Reaproveitar, Reciclar e Recusar), os quais são: uso racional dos recursos naturais e bens públicos; gestão adequada dos resíduos gerados; qualidade de vida no ambiente de trabalho; sensibilização e capacitação dos servidores; compras públicas Sustentáveis; construções sustentáveis (MMA, 2017). E especificamente, observam-se critérios de sustentabilidade em dois documentos legais: Instrução Normativa $\mathrm{n}^{0} 01$, de 19 de janeiro de 2010 (MP0G, 2010) e a Lei Complementar $n^{0}$ 11l, de 01 de fevereiro de 2011 (RIO DE JANEIR0, 2011), que serão as referências que conduzirão a análise comparativa deste artigo com os projetos de obras/ reformas dos prédios públicos presentes no campus da instituição de ensino superior em questão. 


\title{
Sustentabilidade na Construção Civil
}

0 Conselho Brasileiro de Construção Sustentável (CBCS), a Associação Brasileira dos Escritórios de Arquitetura (AsBEA) e outras instituições apresentam diversos princípios básicos que norteiam a construção sustentável, dentre os quais se destacam:

\footnotetext{
a) Aproveitamento de condições naturais e locais;

b) Utilizar mínimo do terreno e integrar-se ao ambiente natural;

c) Implantação e análise do entorno;

d) Não provocar ou reduzir impactos no entorno - paisagem, temperatura e concentração de calor, sensação de bem-estar;

e) Qualidade ambiental interna e externa;

f) Gestão sustentável da implantação da obra;

g) Adaptar-se às necessidades atuais e futuras dos usuários;

h) Uso de matérias-primas que contribuam com a ecoeficiência do processo;

i) Redução do consumo energético e de água;

j) Reduzir, reutilizar, reciclar e dispor corretamente os resíduos sólidos;

k) Introduzir inovações tecnológicas sempre que possível e viável;

l) Educação ambiental: conscientização dos envolvidos no processo (CÂMARA DA INDÚSTRIA DA CONSTRUÇÃo, 2008, p.16).
}

0 principal objetivo de uma construção sustentável é introduzir ao planejamento e à execução de obras esses princípios ambientais que resultam em características positivas àqueles envolvidos direta ou indiretamente nas obras.

\begin{abstract}
Uma obra sustentável leva em consideração todo o projeto da obra desde a sua préconstrução onde devem ser analisados o ciclo de vida do empreendimento e dos materiais que serão usados, passando por cuidados com a geração de resíduos e minimização do uso de matérias-primas com reaproveitamento de materiais durante a execução da obra até o tempo de vida útil da obra e a sustentabilidade da sua manutenção. (MMA, 2020, sem paginação)
\end{abstract}

Viggiano (2012) complementa a definição, demonstrando o mínimo possível de impactos negativos ao meio ambiente e o máximo de autonomia que uma construção sustentável deve alcançar.

Ratificando essa necessidade, o arquiteto Ruy Rezende (FIGUEIRED0, 2011) considera que "a sustentabilidade, como conceito norteador, permeia todas as etapas de um projeto construtivo, uma vez que buscamos uma coerência completa entre o que projetamos, o que é construído e como é utilizado pela sociedade”. Com isso, ao se debater sustentabilidade em todo o processo, concentram-se esforços para que cada etapa do ciclo de vida de uma 
edificação seja concluída levando em conta as preocupações e normas ambientais, sem desperdícios e com qualidade.

De acordo com 0ppenheim e Stuchtey (2015), as empresas em geral estão acostumadas a interagir com o mercado e poucas arriscam quanto à competitividade em favor da inserção das questões ambientais no âmbito de seus processos ou ambiente de trabalho. Os sistemas construtivos utilizados em algumas regiões são ultrapassados, pois utilizam métodos inadequados de trabalho, que pouco consideram a experiência de projetos anteriores, levando à repetição dos mesmos erros em outras obras (VARGAS, 1997) e apresentam muito gasto de material, além do pouco reaproveitamento.

Neste sentido, para inserir a sustentabilidade, é preciso que haja seriedade, rigor, orientação e metas a cumprir. 0 governo começou a estudar métodos para inserir essas práticas em seu próprio domínio. 0 Ministério do Meio Ambiente (MMA, 2017) em 1999 concebeu a ideia de ter uma Agenda Ambiental na Administração Pública (A3P), e após dois anos o programa A3P foi oficialmente criado. 0 objetivo da A3P é estimular a participação de órgãos públicos do país a implementar as práticas de sustentabilidade.

[...] é uma política pública coordenada pelo Ministério do Meio Ambiente, devidamente testada e aprovada. A A3P já foi implantada em mais de 300 órgãos públicos das três instâncias, federal, estadual e municipal, e nos mais diversos setores - incluindo bancos, instituições judiciárias, militares e universidades.

0 Programa A3P é o principal programa de inclusão do tema da sustentabilidade nas atividades administrativas de órgãos públicos de todo país. 0 programa adiciona aos procedimentos tradicionais da administração pública os elementos socioambientais, exatamente aqueles que são exigidos pela modernidade, onde se busca economia, eficiência e sustentabilidade. (MMA, 2017, sem paginação).

Para isso, desenvolveram-se eixos temáticos, onde pode ser observada essa preocupação (MMA, 2017):
a) Uso racional dos recursos naturais e bens públicos;
b) Gestão adequada dos resíduos gerados;
c) Qualidade de vida no ambiente de trabalho;
d) Sensibilização e capacitação dos servidores;
e) Compras públicas sustentáveis;
f) Construções sustentáveis.

De acordo com a A3P, o eixo da construção sustentável tem como principal relevância minimizar os impactos negativos sobre o meio ambiente, pois reduz o excesso de perdas 
materiais e gera economia nos recursos, propiciando uma melhoria de qualidade de vida para aqueles que utilizam uma construção baseada em princípios sustentáveis.

\title{
Prédio Público Sustentável
}

0 gerenciamento de um projeto, conforme afirma Portugal (2017, p. 7), seja uma obra ou reforma, implica em comandar e administrar esta para que seja garantida a solidez e a durabilidade da construção em cumprimento com o planejamento e com o objetivo. Desta forma, faz-se necessária a inclusão de critérios/ itens sustentáveis na fase de concepção do projeto para assim garantir a eficiência e eficácia nas etapas seguintes.

Tendo como base o fato que o Poder Público seja influenciador e deve dar o exemplo quanto ao seu compromisso de zelar pelas riquezas de seu país e pela população, este passa a incluir em suas obras civis a sustentabilidade, surgindo assim o conceito de construções sustentáveis, definida pelo MMA como:

\begin{abstract}
Construção sustentável é um conceito que denomina um conjunto de medidas adotadas durante todas as etapas da obra que visam à sustentabilidade da edificação. Através da adoção dessas medidas é possível minimizar os impactos negativos sobre o meio ambiente além de promover a economia dos recursos naturais e a melhoria na qualidade de vida dos seus ocupantes. (MMA, 2020, sem paginação).
\end{abstract}

0 Senado Federal, em sua cartilha utiliza o termo edifícios públicos sustentáveis e 0 define como sendo:

[...] aquele capaz de proporcionar benefícios na forma de conforto, funcionalidade, satisfação e qualidade de vida sem comprometer a infraestrutura presente e futura dos insumos, gerando o mínimo possível de impacto no meio ambiente e alcançando o máximo possível de autonomia. (VIGGIAN0, 2012, p.9)

De acordo com o Painel de Obras do Ministério do Planejamento, Desenvolvimento e Gestão (ME, 2018), o Brasil tem cerca de 104 mil obras administradas pelo Poder Público. Contudo, o MMA afirma que por mais que o conceito de construção sustentável não seja novo, a maior parte dos prédios públicos não é construída de forma sustentável, havendo pouco aproveitamento, eficiente, de recursos naturais, como água, energia ou corrente de vento. Além do caráter ambiental, as obras públicas federais desde 2010 devem seguir a Instrução Normativa (IN) no 01, de 19 de janeiro de 2010 que: 
Dispõe sobre os critérios de sustentabilidade ambiental na aquisição de bens, contratação de serviços ou obras pela Administração Pública Federal direta, autárquica e fundacional e dá outras providências. (MPOG, 2010, caput)

No capítulo II, art. $4^{0}$ da IN no 01/ 2010, as especificações e demais exigências a respeito dos projetos básico e executivo referem-se à manutenção e operacionalização da edificação, redução no consumo de energia e água e utilização de tecnologias que reduzam o impacto ambiental. Portanto, é de obrigatoriedade o cumprimento dos seguintes itens:

I - uso de equipamentos de climatização mecânica, ou de novas tecnologias de resfriamento do ar, que utilizem energia elétrica, apenas nos ambientes aonde for indispensável;

II - automação da iluminação do prédio, projeto de iluminação, interruptores, iluminação ambiental, iluminação tarefa, uso de sensores de presença;

III - uso exclusivo de lâmpadas fluorescentes compactas ou tubulares de alto rendimento e de luminárias eficientes;

IV - energia solar, ou outra energia limpa para aquecimento de água;

$\mathrm{V}$ - sistema de medição individualizado de consumo de água e energia;

VI - sistema de reuso de água e de tratamento de efluentes gerados;

VII - aproveitamento da água da chuva, agregando ao sistema hidráulico elementos que possibilitem a captação, transporte, armazenamento e seu aproveitamento;

VIII - utilização de materiais que sejam reciclados, reutilizados e biodegradáveis, e que reduzam a necessidade de manutenção;

IX - comprovação da origem da madeira a ser utilizada na execução da obra ou serviço. (MPOG, 2010, art. $4^{0}$ )

0 município do Rio de Janeiro também possui uma lei que exige que a obra de caráter público deve conter critérios sustentáveis. Na Lei Complementar $n^{0} 111$, de $1^{0}$ de fevereiro de 2011, o artigo 184 diz que:

São ações estruturantes relativas às práticas sustentáveis:

I - Incentivar e fomentar, no âmbito do Município:

a) o uso de energia solar;

b) o aproveitamento energético a partir do tratamento de resíduos sólidos;

c) a utilização de coletores de água de chuva e o desenvolvimento de novas alternativas de captação e reutilização de água para usos que não requeiram padrões de potabilidade;

d) adoção de materiais nas fachadas das edificações mais adequados ao clima;

e) ações permanentes de educação ambiental que visem à redução do consumo de energia e água, bem como a utilização de fontes renováveis e não poluentes de energia;

f) mapeamento e adoção de medidas preventivas contra a formação de ilhas de calor em função dos grandes aglomerados urbanos;

g) criação de medida regulatória, mediante entendimentos com o órgão federal gestor do mecanismo de desenvolvimento limpo, para viabilizar a compensação das emissões de carbono por parte dos principais geradores e a implantação de tecnologias limpas e outras ações mitigadoras da poluição do ar (...) (RIO DE JANEIR0, 2011, art. 184) 
Analisando os dois documentos legais, observa-se que o atendimento e a implementação desses critérios e práticas sustentáveis geram redução de energia, água, outros recursos naturais e de resíduos nas fases posteriores à concepção, de modo a proporcionar a economia da manutenção e operacionalização da edificação, como observado também no Decreto n ${ }^{0}$ 7.746/ 2012 (art. $6^{0}$ ) (BRASIL, 2012).

Destacam-se alguns projetos com a presença de critérios de sustentabilidade, que são citados e recomendados pelo Senado Federal para os prédios públicos sustentáveis (VIGGIANO, 2012):

- Projeto de gerenciamento de resíduos provenientes da construção civil. Para que haja um controle maior a respeito dos resíduos gerados na obra, as empresas são obrigadas a destinar seus resíduos a aterros sanitários ou usinas de tratamento de lixo;

- Sistemas de reuso de água (aproveitamento de água de chuva, por exemplo) para evitar desperdícios;

- Procedimentos para reduzir o consumo de energia, a partir da utilização de materiais mais econômicos, como lâmpadas LEDs, luminárias e reatores com alta eficiência;

- Utilização de materiais reciclados, reutilizáveis e biodegradáveis a fim de evitar novas compras ou a geração de novos materiais;

- Utilização de materiais que reduzam a necessidade de manutenção, como materiais mais resistentes ou de melhor qualidade que duram mais;

- Uso de energia solar fotovoltaica, que é uma das mais utilizadas individualmente como energia renovável e limpa;

- Madeira certificada com selo ou reflorestada presente em materiais;

- Utilização de bens e serviços que contenham materiais atóxicos (materiais que não poluem a natureza);

- Utilização de jardins verdes que amenizam a temperatura local;

- Organização no canteiro de obras evita o desperdício e reduz as despesas, além de minimizar o consumo de água e energia, de proporcionar o tratamento de resíduos e reduzir a emissão de gases;

- Coberturas verdes amenizam a incidência de ilhas de calor no meio urbano, a partir da criação de uma reserva de água de chuva, que auxilia na climatização natural dos edifícios;

- Utilização de sistemas passivos de climatização com paredes ventiladas e coberturas verdes; 
- Utilização da iluminação natural, principalmente quando o edifício é projetado na orientação correta e permite a passagem de luz, sem haver excesso de calor;

- Projetos de gerenciamento de resíduos sólidos recicláveis, não recicláveis e rejeitos.

\section{METOD0LOGIA}

0 estudo tem caráter qualitativo, pois se trabalha com padrões, dados subjetivos e opiniões (LAKATOS E MARCONI, 2003). Classifica-se, quanto aos objetivos, como pesquisa exploratória, proporcionando maior familiaridade com o tema, a partir do entendimento dos critérios de sustentabilidade na fase de concepção/ projeto da obra do prédio (GIL, 2017). Com relação aos procedimentos de pesquisa, enquadra-se como uma pesquisa documental, tendo como referência a Instrução Normativa $n^{0}$ 01, de 19 de janeiro de 2010 (MP0G, 2010) e a Lei Complementar $\mathrm{n}^{0}$ 111, de 01 de fevereiro de 2011 (RI0 DE JANEIR0, 2011), e bibliográfica, por meio de escritos e eletrônicos já publicados. Realiza-se também um estudo de caso (DIEHL e TATIM, 2004), que procura identificar os critérios sustentáveis presentes nas obras e reformas de uma Instituição de Ensino Superior (IES), como o CEFET/RJ.

\section{RESULTADOS E DISCUSSÃ0}

0 estudo busca verificar a presença de critérios sustentáveis nos projetos básicos e executivos das obras recentemente realizadas no Centro Federal de Educação Tecnológica Celso Suckow da Fonseca (CEFET/RJ) e se os mesmos atendem à Instrução Normativa $n^{0}$ 01/ 2010 (MP0G, 2010) e à Lei Complementar nº 111/ 2011 (RI0 DE JANEIR0, 2011).

0 Centro Federal de Educação Tecnológica Celso Suckow da Fonseca (CEFET/RJ) é uma instituição federal, vinculada ao Ministério da Educação e Cultura (MEC), que se dispõe a oferecer ensino profissionalizante médio-técnico, cursos técnicos e superiores, e apresenta um sistema multicampi com dois campi na cidade e seis campi no estado do Rio de Janeiro: Maracanã, Maria da Graça, Angra dos Reis, Itaguaí, Nova Friburgo, Nova Iguaçu, Petrópolis e Valença (CEFET/RJ, 2017).

Expandida academicamente e em área física, o campus na cidade do Rio de Janeiro, no bairro do Maracanã, será o local onde serão analisados os projetos das obras/ reformas, que ocupam um terreno de $34.382 \mathrm{~m}^{2}$, cuja área construída apresenta $64.818 \mathrm{~m}^{2}$, 11 blocos e seis pavilhões de edifícios. São 72 salas de aula, 166 laboratórios e oficinas, nove auditórios, uma 
biblioteca, duas videotecas, um complexo esportivo com quadras, ginásio, piscina e pista de atletismo, entre outros espaços de natureza educativa (CEFET/RJ, 2018).

Toda obra possui projetos que definem suas características e a Lei no 8.666/1993 define dois tipos de projeto: o básico e o executivo. De acordo com o inciso IX do artigo sexto, o projeto básico possui um conjunto de elementos necessários e suficientes com características e precisão a respeito dos estudos técnicos preliminares incluindo o tratamento adequado ao impacto ambiental gerado pelo empreendimento. Neste tipo de projeto é possível ter acesso aos seguintes itens:

a) Desenvolvimento da solução escolhida de forma a fornecer visão global da obra e identificar todos os seus elementos constitutivos com clareza;

b) Soluções técnicas globais e localizadas, suficientemente detalhadas, de forma a minimizar a necessidade de reformulação ou de variantes durante as fases de elaboração do projeto executivo e de realização das obras e montagem;

c) Identificação dos tipos de serviços a executar e de materiais e equipamentos a incorporar à obra, bem como suas especificações que assegurem os melhores resultados para o empreendimento, sem frustrar o caráter competitivo para a sua execução;

d) Informações que possibilitem o estudo e a dedução de métodos construtivos, instalações provisórias e condições organizacionais para a obra, sem frustrar 0 caráter competitivo para a sua execução;

e) Subsídios para montagem do plano de licitação e gestão da obra, compreendendo a sua programação, a estratégia de suprimentos, as normas de fiscalização e outros dados necessários em cada caso;

f) Orçamento detalhado do custo global da obra, fundamentado em quantitativos de serviços e fornecimentos propriamente avaliados. (BRASIL, 1993, art. $6^{\circ}$, inciso IX, itens)

No inciso X, a lei descreve o projeto executivo como conjunto de elementos necessários e suficientes à execução completa da obra (BRASIL, 1993). Sendo assim, tomando como base essas definições, serão investigados os projetos básico e executivo das obras do campus (MP0G, 2015, 2017a, 2017b e 2017c), para que seja feita a análise a respeito dos materiais utilizados em todas as fases da obra e da incorporação de critérios sustentáveis nos projetos.

Nos últimos anos foram realizadas diversas obras no campus Maracanã do CEFET/RJ, como reformas, instalações prediais, recuperação de fachadas, obras de construção de novos blocos, construção da quadra poliesportiva, substituição de telhados, instalação de subestação, dentre outras citadas no Quadro 1.

Quadro 1 - Obras para análise dos critérios de sustentabilidade.

\begin{tabular}{|cccc|}
\hline Empresa & CNPJ & $\begin{array}{c}\text { Ano de previsão } \\
\text { da obra }\end{array}$ & $\begin{array}{c}\text { Especificação da } \\
\text { obra }\end{array}$ \\
\hline STC Engenharia & $\begin{array}{c}09.640 .008 / 0001- \\
97\end{array}$ & 2015 & $\begin{array}{c}\text { Obra de } \\
\text { Construção do } \\
\text { bloco F }\end{array}$ \\
\hline
\end{tabular}




\begin{tabular}{|cccc|}
\hline VITAL MESTRES & $27.113 .682 / 0001-03$ & 2017 & $\begin{array}{c}\text { Quadra } \\
\text { poliesportiva }\end{array}$ \\
\hline VITAL MESTRES & $27.113 .682 / 0001-03$ & 2017 & $\begin{array}{c}\text { Reforma da } \\
\text { academia para } \\
\text { adequação para } \\
\text { restaurante } \\
\text { universitário }\end{array}$ \\
\hline ARTHE0 & $25.159 .672 / 0001-75$ & 2017 & $\begin{array}{c}\text { Reforma } \\
\text { Campus III }\end{array}$ \\
\hline
\end{tabular}

Fonte: MPOG (2015, 2017a, 2017b, 2017c).

Os quatro projetos englobam reformas de antiga estrutura e a construção de uma nova no campus Maracanã. Ao ser realizada uma reforma ou uma construção de um novo prédio, como revelado por Viggiano (2012), o objetivo principal é que as construções sejam cada vez mais independentes e capazes de se "autossustentar”, como em um caso de gerar sua própria energia.

Na verificação quanto à presença ou ausência dos itens nos projetos das obras, que são exigidos pela Instrução Normativa no 01/ 2010 (MP0G, 2010), pela Lei Complementar no 111/ 2011 (RI0 DE JANEIR0, 2011) e por um dos autores, renomados na área de obras públicas sustentáveis, Viggiano (2012), elaborou-se um quadro comparativo entre os projetos e os critérios de sustentabilidade a serem atendidos (Quadro 2).

Quadro 2 - Análise comparativa dos critérios de sustentabilidade com os projetos de obras do CEFET/RJ e do IFSULMINAS (Complexo esportivo).

\begin{tabular}{|l|ccccc|}
\hline \begin{tabular}{c} 
Critérios \\
\multicolumn{1}{c|}{$\begin{array}{c}\text { Sustentabilida } \\
\text { de }\end{array}$}
\end{tabular} & $\begin{array}{c}\text { Construção } \\
\text { do bloco F }\end{array}$ & $\begin{array}{c}\text { Quadra } \\
\text { poliesportiva }\end{array}$ & $\begin{array}{c}\text { Restaurante } \\
\text { universitário }\end{array}$ & $\begin{array}{c}\text { Reforma } \\
\text { Campus } \\
\text { III }\end{array}$ & IFSULMINAS \\
\hline $\begin{array}{l}\text { 1- Sistema de } \\
\text { reaproveitame } \\
\text { nto de águas } \\
\text { pluviais }\end{array}$ & Ausente & Ausente & Ausente & Ausente & Presente \\
\hline $\begin{array}{l}2- \\
\text { Implantação } \\
\text { de telhados } \\
\text { verdes }\end{array}$ & Ausente & Ausente & Ausente & Ausente & Ausente \\
\hline $\begin{array}{l}3-\text { Utilização } \\
\text { de lâmpadas } \\
\text { de baixo } \\
\text { consumo }\end{array}$ & Presente & Presente & Presente & Presente & Presente \\
\hline $\begin{array}{l}4-\text { Instalação } \\
\text { de sensores de } \\
\text { presença }\end{array}$ & Presente & Presente & Presente & Presente & Presente \\
\hline
\end{tabular}




\begin{tabular}{|c|c|c|c|c|c|}
\hline $\begin{array}{l}5 \text { - Pintar } \\
\text { paredes, tetos } \\
\text { e pisos de } \\
\text { cores claras }\end{array}$ & Presente & Presente & Presente & Presente & Presente \\
\hline $\begin{array}{l}6 \text { - Geração de } \\
\text { energia por } \\
\text { sistema } \\
\text { fotovoltaico ou } \\
\text { eólico }\end{array}$ & Ausente & Ausente & Ausente & Ausente & Ausente \\
\hline $\begin{array}{l}7 \text { - Uso de } \\
\text { madeira } \\
\text { certificada ou } \\
\text { reflorestada }\end{array}$ & Presente & Presente & Presente & Presente & Presente \\
\hline $\begin{array}{l}8 \text { - Projeto } \\
\text { luminotécnico } \\
\text { direcionado à } \\
\text { eficiência } \\
\text { energética }\end{array}$ & Presente & Presente & Presente & Presente & Presente \\
\hline $\begin{array}{l}9 \text { - Reciclagem } \\
\text { de materiais } \\
\text { descartados }\end{array}$ & Presente & Presente & Presente & Presente & Presente \\
\hline $\begin{array}{l}10 \text { - Troca das } \\
\text { válvulas de } \\
\text { descarga por } \\
\text { caixas } \\
\text { acopladas }\end{array}$ & Presente & Presente & Presente & Presente & Presente \\
\hline $\begin{array}{l}11 \text { - Instalação } \\
\text { de torneiras } \\
\text { com } \\
\text { desligamento } \\
\text { automático }\end{array}$ & Presente & Presente & Presente & Presente & Presente \\
\hline $\begin{array}{l}12 \text { - Licitações } \\
\text { e compras } \\
\text { sustentáveis }\end{array}$ & Presente & Presente & Presente & Presente & Presente \\
\hline
\end{tabular}

Na análise do quadro 2, é possível perceber itens considerados básicos nos projetos, como a utilização de sensores de presença ou torneiras temporizadoras. Além de pinturas em tons claros que contribuem com um aproveitamento da luminosidade natural e à noite propaga melhor a luz no ambiente, implicando na utilização de menos lâmpadas.

Quanto aos itens ausentes nos projetos, acredita-se que se demande um investimento maior para a sua viabilização, bem como um estudo mais aprofundado para a sua implantação nos prédios. Cabe lembrar que no início do ano de 2019, foi inaugurada uma cisterna de reaproveitamento de águas pluviais no pavilhão da Segurança do Trabalho no campus Maracanã do CEFET/RJ (DISAI, 2018). 
Conforme visto nos projetos de obras analisados, alguns itens do projeto podem ser modificados durante a contratação do serviço, o que foi observado, no item eficiência energética. A utilização de lâmpadas fluorescentes que foram trocadas por lâmpadas mais eficientes como as de LED, que possuem maior economia e maior eficiência energética (JMC ELÉTRICA, 2019).

A utilização de descargas a vácuo com caixa acoplada ou redutores de descarga, que geram economia de água, também foram observados nos projetos dos banheiros; além da previsão de instalações de torneiras temporizadas ou com sensores automáticos. É comprovado que o uso desses materiais evita desperdícios.

No entanto, poderiam ter sido realizadas obras e modificações nos telhados das estruturas para fins sustentáveis. No projeto da quadra poliesportiva, verifica-se a previsão/ uso de telhas de alumínio, e poderia ter sido utilizado um telhado verde ou algo que melhorasse a acústica da construção. Os telhados também poderiam ter sido projetados para reutilizar as águas de chuva, com fins para utilização nas descargas dos banheiros ou para irrigação dos jardins que se encontram próximos aos prédios das obras do bloco $F$, do restaurante universitário e da quadra.

Em comparação ao Instituto Federal do Sul de Minas Gerais (IFSULDEMINAS), que tem similaridade com o CEFET/RJ por serem instituições públicas (federal) de ensinos técnico e superior, também preocupadas com a promoção da sustentabilidade, realizou-se uma análise entre os projetos de obra de reforma/construção do complexo esportivo das duas instituições, quanto à presença de critérios sustentáveis, que também é verificada no Quadro 2. Observouse que a obra de reforma para transformar em Complexo Esportivo no campus avançado de Três Corações no IFSULDEMINAS incluiu a reutilização de águas pluviais e a instalação de reservatórios para utilizá-las. Esses critérios influenciam nos custos finais dos projetos, porém retornam em benefícios econômicos (MEC, 2017).

0 artigo, portanto, demonstra que, mesmo que os projetos de obras no CEFET/RJ tenham alcançado 75\% dos critérios de sustentabilidade exigidos nas legislações (Quadro 2), deve-se investir em estudos mais aprofundados para que os $25 \%$ restantes dos critérios sejam viabilizados durante a concepção do projeto de arquitetura com a participação, em conjunto, das equipes de licitação, de orçamento e dos projetos complementares. Sendo assim, deve ser desenvolvida uma agenda de critérios sustentáveis para as futuras obras nos campi do CEFET/RJ, que baseia-se no art. $4^{0}$ da Instrução Normativa $n^{0}$ 01/2010 (MP0G, 2010), no art. 184 da Lei Complementar $n^{0}$ 11l/ 2011 (RI0 DE JANEIR0, 2011) e na experiência do renomado autor Viggiano (2012), que contemple: 
1. Sistema de reaproveitamento de águas pluviais;

2. Implantação de telhados verdes;

3. Utilização de lâmpadas de baixo consumo;

4. Instalação de sensores de presença;

5. Cores claras para paredes, tetos e pisos;

6. Geração de energia por sistema fotovoltaico ou eólico;

7. Uso de madeira certificada ou reflorestada;

8. Projeto luminotécnico direcionado à eficiência energética;

9. Reciclagem de materiais descartados;

10. Troca das válvulas de descarga por bacias com caixas acopladas; e

11. Instalação de torneiras com desligamento automático.

\section{CONCLUSÃO}

A sustentabilidade é um tema de grande abrangência desde o fim do século passado. Isto porque o crescimento econômico e populacional disparou e ressaltou aos olhos do governo. Sendo assim este artigo teve como intuito abordar a temática da sustentabilidade nas construções da Administração Pública, considerando os materiais utilizados para tal fim.

A construção civil é um dos setores que gera grande impacto na economia e utiliza recursos naturais em abundância. A utilização de itens sustentáveis neste setor proporciona grande impacto na cadeia mundial, desde a utilização das matérias-primas até o descarte dos resíduos gerados nas obras ou demolições. Por isso, a necessidade de transformar esta situação, reduzindo os desperdícios.

A Agenda Ambiental na Administração Pública fez com que os órgãos aumentassem o interesse em manter um projeto sustentável e nos últimos anos, agregou organizações ao programa de responsabilidade socioambiental, fazendo com que mais pessoas repensassem sobre o consumo de materiais e a reduzir ou reciclar antes de adquirir um novo produto. Verificar a presença de critérios de sustentabilidade em prédios públicos implica em um mercado mais competitivo neste assunto.

As instituições de ensino, como CEFET/RJ e o IFSULDEMINAS, são responsáveis por gerar o futuro do país, pois transformam a percepção daqueles que usam os materiais da edificação e formam a mão de obra da sociedade. São influenciadoras e por isso, torna-se importante visualizar de fato a adesão, por elas, dos critérios de sustentabilidade em seus 
projetos de obras, transformando-se num modelo a ser seguido, principalmente quando se tem uma agenda de critérios de sustentabilidade para seus projetos.

Portanto, verificou-se neste artigo, que se fez necessário o conhecimento de detalhes (de materiais e serviços) na elaboração de um projeto básico para uma construção, bem como da própria legislação pertinente. Contudo, percebe-se a necessidade de um estudo mais aprofundado para a incorporação de alguns critérios, principalmente nas reformas a fim de viabilizar o reaproveitamento de águas de chuva ou mesmo a construção do telhado verde. É reconhecido que a adesão de alguns critérios sustentáveis torna o projeto mais custoso para ser executado, porém o retorno financeiro deve ser avaliado, pois gera benefícios e melhorias ao redor daqueles que desfrutam do ambiente.

A partir de estudos bibliográficos e levantamento de dados em outros órgãos, esperase que se adote uma agenda de critérios de sustentabilidade para prédios públicos de instituições de ensino, e que seja um padrão a ser consultado e seguido.

E que no futuro, possa ser desenvolvido um modelo de agenda para os órgãos de caráter privado, de maneira que a sustentabilidade não seja vista como um diferencial de mercado, mas que seja um item essencial na construção de empreendimentos e obras civis.

\section{REFERÊNCIAS BIBLIOGRÁFICAS}

BRASIL. PRESIDÊNCIA DA REPÚBLICA. Lei n⿳0 8.666, de 21 de junho de 1993. Regulamenta 0 art. 37, inciso XXI, da Constituição Federal, institui normas para licitações e contratos da Administração Pública e dá outras providências. Disponível em: http://www.planalto.gov.br/ccivil_03/Leis/18666cons.htm. Acessado em 07 jun. 2019.

. PRESIDÊNCIA DA REPÚBLICA. Decreto $\mathrm{n}^{\mathbf{0}} \mathbf{7 . 7 4 6}$, de 5 de junho de 2012. Regulamenta 0 art. $3^{\circ}$ da Lei $\mathrm{n}^{0}$ 8.666, de 21 de junho de 1993, para estabelecer critérios e práticas para a promoção do desenvolvimento nacional sustentável nas contratações realizadas pela administração pública federal direta, autárquica e fundacional e pelas empresas estatais dependentes, e institui a Comissão Interministerial de Sustentabilidade na Administração Pública - CISAP. Disponível em: http://www.planalto.gov.br/ccivil_03/_Ato20112014/2012/Decreto/D7746.htm Acessado em 5 Jun. 2020

CÂMARA DA INDÚSTRIA DA CONSTRUÇÃO. Guia de Sustentabilidade na Construção. Belo Horizonte: FIEMG, 2008. Disponível em: http://www.sinduscon-mg.org.br/site/arquivos/up/comunicacao/guia_sustentabilidade.pdf Acessado em 25 ago. 2020.

CBCS - CONSELHO BRASILEIRO DE CONSTRUÇÃO SUSTENTÁVEL. Aspectos da Construção Sustentável no Brasil e na Promoção de Políticas Públicas. Subsídios para a promoção da Construção Civil Sustentável. CBCS. PNUMA. MMA. 2014. Disponível em: http://www.cbcs.org.br/website/aspectos-construca0sustentavel/show.asp?ppgCode=31E2524C-905E-4FC0-B784-118693813AC4 Acessado em 26 ago. 2020.

CEFET/RJ - CENTRO FEDERAL DE EDUCAÇ̃̃O TECNOLÓGICA CELSO SUCKOW DA FONSECA. CEFET/RJ Histórico. 2017. Disponível em http://www.cefet-rj.br/index.php/2015-06-02-16-38-34 .Acessado em 20 nov. 2019.

CEFET/RJ - CENTRO FEDERAL DE EDUCAÇ̃̃O TECNOLÓGICA CELSO SUCKOW DA FONSECA. Campus Maracanã Apresentação. 2018. Disponível em: http://www.cefet-rj.br/index.php/maracana Acessado em 21 nov. 2019. 
COSTA, E.D., MORAES, C.S.B. Construção Civil e a Certificação Ambiental: Comparação das Certificações LEED (Leadership in Energy and Environmental Design) e AQUA (Alta Qualidade Ambiental). Engenharia Ambiental. Espírito Santo do Pinhal. v.10, n. 3, p. $160-$ 177, maio/jun 2013. Disponível em: https://www.researchgate.net/publication/334695945_CONSTRUCA0_CIVIL_E_A_CERTIFICACA0_AMBIENTAL_AN ALISE_COMPARATIVA_DAS_CERTIFICACOES_LEED_LEADERSHIP_IN_ENERGY_AND_ENVIRONMENTAL_DESIGN_E_AQ UA_ALTA_QUALIDADE_AMBIENTAL_Engenharia_Ambiental_Pesquisa_e_Tec Acessado em 12 nov. 2019.

DIEHL, A. A.; TATIM, D. C. Pesquisa em Ciências Sociais Aplicadas. São Paulo: Editora Pearson, 2004.

DISAI - DIVISÃO DE ESTRATÉGIA PARA SUSTENTABILIDADE AMBIENTAL INSTITUCIONAL. Relatório Parcial do Projeto Consumo Consciente de Água - Campus Maracanã Diagnóstico, aplicação e resultados do Checklist Fase l: Banheiros, Cozinhas, Laboratórios e Vestiários. CEFET/RJ. Abril, 2018. Disponível em: http://sustentabilidade.cefet-rj.br/agua/ Acessado em 26 set. 2019.

FIGUEIREDO, R. Sustentabilidade: 0 Case do Edifício Cidade Nova. Direcional Condomínios. Vila Mariana, São Paulo - SP. Rosali, 2011. Disponível em: https://www.direcionalcondominios.com.br/sindicos/materias/item/1670sustentabilidade-0-case-do-edificio-cidade-nova-rj.html Acessado em 21 mar. 2019.

GIL, A.C. Como elaborar projetos de pesquisa. 6 ed. São Paulo: Atlas, 2017.

JMC ELÉTRICA. Qual a diferença entre lâmpadas incandescentes, fluorescentes e lâmpadas de led? Iluminação. Lâmpadas. 2019. Disponível em http://jmc.com.br/fluorescente-lampadas-de-led/ Acessado em 10 out 2019.

LAKATOS, E. M.; MARCONI, M. A. Fundamentos de metodologia cientifica. São Paulo: Atlas, 2003.

ME - MINISTÉRIO DA ECONOMIA. Painel de 0bras. 2018. Disponível em http://transferenciasabertas.planejamento.gov.br/QvAJAXZfc/opendoc.htm?document=painelcidadao.qvw\&lang =en-US\&host=0VS\%40srvbsaiasprd01Ganonymous=true Acessado em 03 nov. 2018.

MEC - MINISTÉRIO DE EDUCAÇÃO E CULTURA. RDC Eletrônico № 4/2017. Contratação de empresa especializada para construção e reforma de Ginásio Poliesportivo, auditório e laboratórios do Campus Avançado Três Corações do IFSULDEMINAS, conforme condições, quantidades e exigências estabelecidas neste Edital e seus anexos. 2017. Disponível em https://portal.ifsuldeminas.edu.br/index.php/estrutura/110-proad-geral/1428-rdc-2017-uasg158137 Acessado em 01 nov. 2019.

MMA - MINISTÉRIO DO MEI0 AMBIENTE. Secretaria de Articulação Institucional e Cidadania Ambiental. A3P. Agenda Ambiental na Administração Pública. Brasília. 2017. Disponível em: http://a3p.mma.gov.br/Acessado em 25 mai. 2019.

MMA - MINISTÉRIO DO MEI0 AMBIENTE. Construções sustentáveis. Brasília. 2020. Disponível em: http://a3p.mma.gov.br/construcoes-sustentaveis/Acessado em 22 abr. 2020.

MPOG - MINISTÉRIO DO PLANEJAMENTO, DESENVOLVIMENTO E GESTÃO. Instrução Normativa $\mathbf{n}^{\circ} 01$ de 19 de janeiro de 2010. Dispõe sobre os critérios de sustentabilidade ambiental na aquisição de bens, contratação de serviços ou obras pela Administração Pública Federal direta, autárquica e fundacional e dá outras providências. Governo Digital. Disponível em https://www.normasbrasil.com.br/norma/?id=78139 . Acessado em 03 nov. 2018.

MPOG - MINISTÉRIO DO PLANEJAMENTO, DESENVOLVIMENTO E GESTÃO API de Compras Governamentais: $\begin{array}{llll}\text { CONCORRÊNCIA } & 153010.03 .00006 .2014 & 2015 . & \text { Disponível }\end{array}$ http://compras.dados.gov.br/licitacoes/doc/licitacao/15301003000062014 Acessado em 28 set 2019.

MPOG - MINISTÉRIO DO PLANEJAMENTO, DESENVOLVIMENTO E GESTÃO. API de Compras Governamentais: $\begin{array}{lllll}\text { CONCORRÊNCIA } & 153010.03 .00001 .2017 . & 2017 a & \text { Disponível } & \mathrm{em}\end{array}$ http://compras.dados.gov.br/licitacoes/doc/licitaca0/15301003000012017 Acessado em 28 set 2019.

MPOG - MINISTÉRIO DO PLANEJAMENTO, DESENVOLVIMENTO E GESTÃO. API de Compras Governamentais:

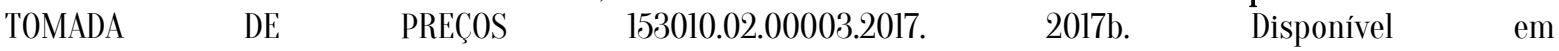
http://compras.dados.gov.br/licitacoes/doc/licitaca0/15301002000032017 Acessado em 28 set 2019. 
MPOG - MINISTÉRIO DO PLANEJAMENTO, DESENVOLVIMENTO E GESTÃO. API de Compras Governamentais: TOMADA DE PREÇOS 153010.02.00001.2017. $2017 \mathrm{c}$. Disponível http://compras.dados.gov.br/licitacoes/doc/licitacao/15301002000012017 Acessado em 28 set 2019.

OPPENHEIM, J.; STUCHTEY, M. Like it or not, sustainability is now core to your business. Fortune, v.24, set. 2015. Disponível em: http://fortune.com/2015/09/24/sustainability-practices-in-business-intel-unilever-wal-martdupont/. Acessado em 27 out. 2018.

PORTUGAL, M.A. Como gerenciar projetos de construção civil: do orçamento à entrega da obra. Rio de Janeiro: Brasport, 2017.

RIO DE JANEIRO MUNICÍPIO. Lei Complementar $\mathbf{n}^{\mathbf{0}} 111$ de $\mathbf{1}^{\mathbf{0}}$ de fevereiro de 2011. Câmara Municipal do Rio de Janeiro - RJ. Dispõe sobre a política urbana e ambiental do município, institui o plano diretor de desenvolvimento urbano sustentável do município do Rio de Janeiro e dá outras providências. Disponível em: https://leismunicipais.com.br/al/plano-diretor-rio-de-janeiro-rj. Acessado em 03 nov. 2018.

VARGAS, C.L.S.et. al. Avaliação de perdas em obras. Aplicação de metodologia expedita. In: ENCONTRO NACIONAL DE ENGENHARIA DE PRODUÇÃO, 17, Gramado, RS, 1997. Disponível em: http://fortune.com/2015/09/24/sustainability-practices-in-business-intel-unilever-wal-mart-dupont/ Acessado em 25 ago. 2020.

VIGGIANO, M.H.S. Edifícios públicos sustentáveis, 3. ed. rev. em mar. de 2012 - Brasília: Subsecretaria de Edições Técnicas. Disponível em http://cpsustentaveis.planejamento.gov.br/assets/conteudo/uploads/cartilha--conteudo---20120329---cd.pdf. Acessado em 28 out. 2018. 